\title{
A $50 \Omega$ Microstrip Line Fed Shorted Hexagonal Microstrip Antennas with Reduced Cross-Polarization
}

\author{
S. M. Rathod ${ }^{1}$ (D, R. N. Awale ${ }^{1}$ (D), K. P. Ray ${ }^{2}$ (D) \\ ${ }^{I}$ Department of Electrical Engineering, Veermata Jijabai Technological Institute (VJTI) \\ Mumbai, Maharashtra State, India-400019. \\ rathod.shivraj@gmail.com,rnawale@vjti.org.in \\ ${ }^{2}$ Department of Electronics Engineering, Defence Institute of Advanced Technology (DIAT) \\ Pune, Maharashtra State, India-411025. \\ kpray@diat.ac.in
}

\begin{abstract}
A Hexagonal Microstrip Antenna (HMSA) is an approximation to a Circular MSA (CMSA), which is not symmetrical over two principal planes, unlike a CMSA. Consequently, two types of feed positions are feasible for each $X$ and $\boldsymbol{Y}$-axes. When a quarter-wave transformer or inset feed is used to match the edge impedance of the HMSA, it becomes asymmetrical over the feed axis ( $E$-plane), which leads to increase in the crosspolarization level in the $\boldsymbol{H}$-plane. In this paper, to reduce the crosspolarization level of HMSA along $H$-plane and to match the edge

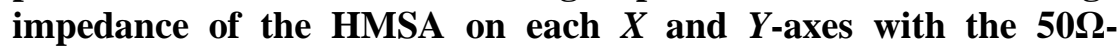
Microstrip (MS)-line-feed, a single and a pair of shorting posts have been used. The current distribution of the shorted HMSA is changed due to the loading of shorting posts into the patch, which in-turns help to match the edge input impedance. A detailed investigation on the characteristics of the shorted HMSA with modified fundamental mode frequencies has been presented. The co-polarization to crosspolarization ratios (CTCR) in $\boldsymbol{H}$-plane of the HMSA with a pair of shorting posts has been reduced substantially by more than $20 \mathrm{~dB}$ at the broadsight direction in comparison with that of an HMSA with a single shorting post or with an inset. The simulated results of the

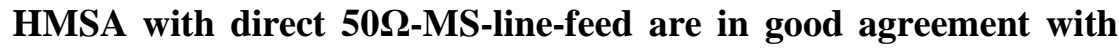
measured ones.
\end{abstract}

Index Terms - Cross-polarization, Fundamental mode, Inset feed, Edge fed hexagonal antenna, Shorting post.

\section{INTRODUCTION}

In recent times, the idea of creating antenna-on-chip (AOC) with MS-line feed has gained increased attention, due to its feature such as planar geometry, low profile outlook, simplicity in fabrication and integration compatibility with other microwave circuits. Owing to this, research efforts are directed to design an integrable antenna on a single substrate with improved performance [1]-[3]. However, the MS-line feed along with their compatible MS components, start radiating which leads to increased losses, cross-polarization levels and parasitic coupling effects leading to a decrease in its gain. These effects make the design more complex as the operating frequency increases [3]-[8]. Also, the impedance 


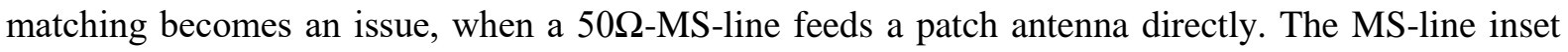
feed takes care of the impedance matching and also has an advantage that it can be fabricated on the same substrate layer, facilitating the direct integration of monolithic-microwave integrated circuits (MMICs) and active devices, retaining the planarity. However, an inset feed introduces a physical deformation in the geometry of the antenna, which makes the antenna asymmetrical. Consequently, the cross-polarization level increases [2], [3]. Rectangular and Circular MSAs have been designed with simple MS-line feed (without an inset), which have reduced cross-polarization [9]-[13]. Also, detailed investigation of various resonant modes generated in a shorted MS-line fed square MSA has been reported in [14]. Recently, new configurations of probe-fed MSAs was reported [15], [16]. These antenna configurations have reduced cross-polarization in $H$-plane using a pair of symmetric circular clusters of shorting pins [15] and array of shorting pins along with a pair of shorting walls [16]. However, both these configurations do not retain the planarity.

An HMSA configuration is an approximation of a CMSA [17]. It is advantageous to obtain broad $\mathrm{BW}$, as compared to the CMSA because its straight edges provide more coupling between the parasitic and fed patch when used in gap-coupled broadband configurations [7]. Two HMSA configurations are

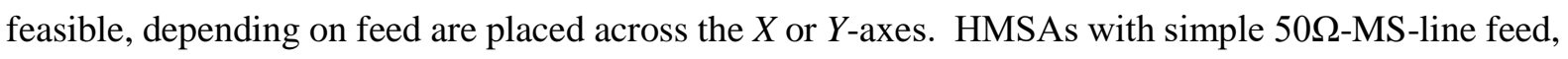
without using any external matching section or inset has not yet been investigated. In this paper, an investigation of both the shorted HMSAs, using a single and a pair of shorting posts, which are fed by $50 \Omega$-MS-line, have been presented. Analysis of both the shorted HMSAs has been performed at modified fundamental mode frequency in regards to the different positions of shorting posts. HMSAs with the pair of shorting posts gives more than $20 \mathrm{~dB}$ suppression of cross-polarization level in boresight direction in comparison with that of a single shorted HMSA, in $H$-plane. This suppression is $10 \mathrm{~dB}$ higher as compared to that reported for the RMSA with a pair of shorting posts [10], [11]. Simulation has been performed using IE3D software [18]. Theoretical and measured characteristics of these proposed shorted HMSAs are in good agreement. These proposed configurations can be suitably scaled for use in various communication systems.

\section{ANALYSIS OF AN INSET FED HMSA}

First, an analysis of a conventional inset-fed both HMSAs, with the side length $S$ (as shown in Fig. $1)$, is carried out. The conventional inset fed HMSA structures are realized using Arlon substrate with $\varepsilon_{r}=2.5, h=1.59 \mathrm{~mm}$ and $\tan \delta=0.003$ at fundamental mode frequency $F_{F}=1.8 \mathrm{GHz}$. The side length of HMSAs $S=32.8 \mathrm{~mm}$ is calculated using formulations given in [7], [17]. Along the $X$ and the $Y$-axes, two feed positions can be used for excitation of the dominant mode of the HMSA, as illustrated in Fig. 1. The vertex input impedance of the HMSA, as illustrated in Fig. 1 (a) is higher than that of 1 (b), which typically varies between 400 to $500 \Omega$, so it is required to use inset feed for $50 \Omega$ impedance 


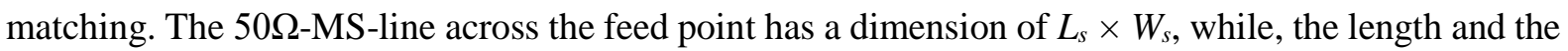
width of the inset feed across MS-line is $L_{n} \times W_{n}$, respectively. Thus, $L_{n}$ for Fig. 1(a) will be slightly longer than that of Fig. 1(b). The inset feed realized by concerning a notch length $\left(L_{\mathrm{n}}\right)$ and width $\left(W_{n}\right)$, that leads to introduce a junction capacitance [1-3]. The optimized inset dimensions $\left(L_{\mathrm{n}} \times W_{n}\right)$ for the $Y$ and $X$-axes HMSA configurations are $21.46 \times 1.53 \mathrm{~mm}^{2}$ and $19.62 \times 1.30 \mathrm{~mm}^{2}$, respectively.

The simulated reflection coefficient plots for HMSA fed across the $X$ and the $Y$-axes, are depicted in Fig. 2 (a). Fig. 3 illustrated their respective radiation characteristics in $E$ and $H$-plane. The simulated fundamental mode frequencies for configurations with feed axis along the $Y$ and the $X$-axes are 1.795 $\mathrm{GHz}$ and $1.801 \mathrm{GHz}$, respectively. The surface current plots for inset feed HMSAs have been depicted in Figure 2 (b) and (c) for feed along $Y$ and $X$, respectively. The resonant length of the HMSA in Fig. 1(b) is slightly smaller than that of Fig. 1(a), thus the frequency of the configuration of Fig. 1(b), which is fed along $\mathrm{X}$ axis, is marginally higher. The radiation patterns are in broadside direction with increased cross-pol levels. In case of inset fed HMSA along the $Y$-axis, the simulated $E$ and $H$-plane half-power beam widths (HPBWs) is $108^{\circ}$ and $79^{\circ}$, respectively. Similarly, for the case of inset fed HMSA along the $X$-axis, the simulated HPBWs in $E$ and $H$-planes are $106^{\circ}$ and $79^{\circ}$, respectively.

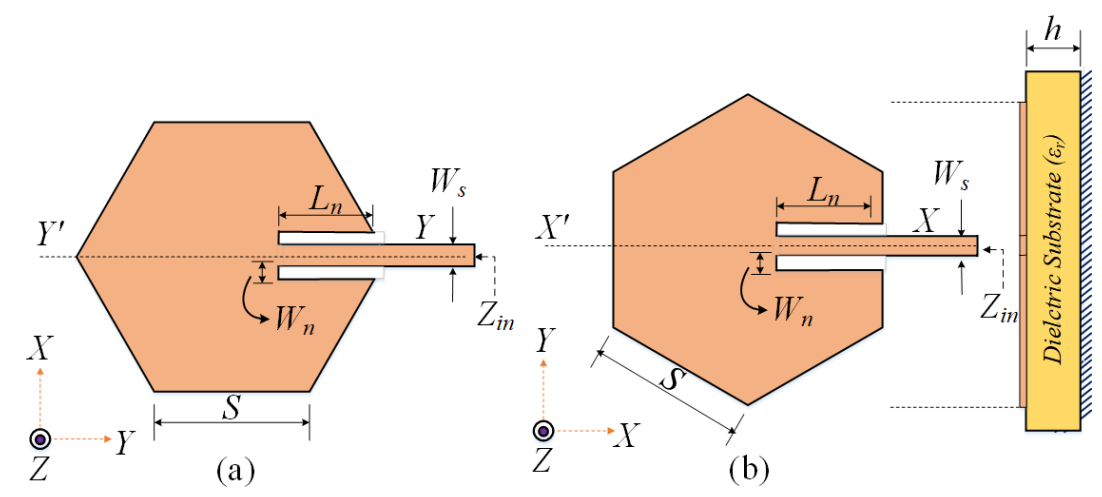

Fig.1. The geometry of a conventional inset fed HMSA fed along (a) $Y$-axis and (b) $X$-axis.

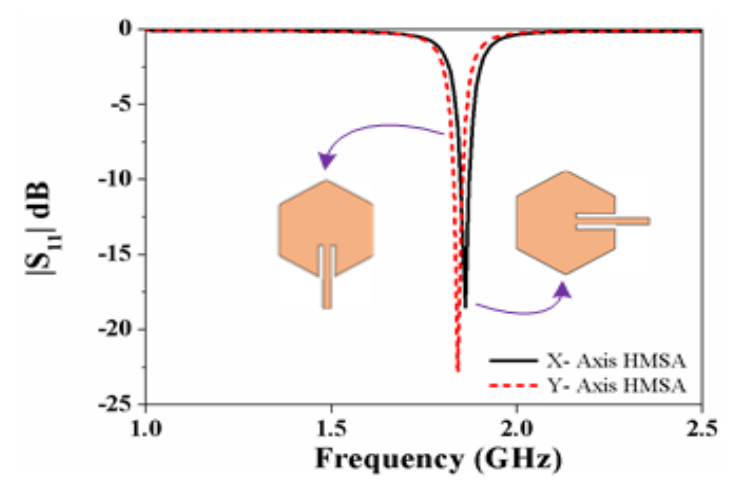

(a)

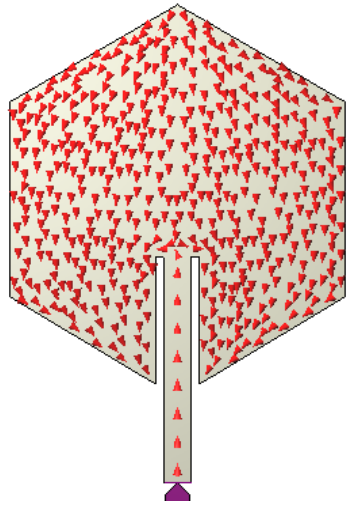

(b)

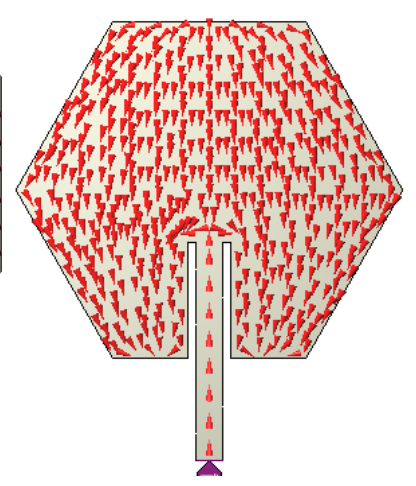

(c)

Fig.2. (a) Simulated reflection coefficient plot and surface current distribution with feed along (b) $Y$-axis at $1.795 \mathrm{GHz}$ and (c) $X$-axis at $1.801 \mathrm{GHz}$ of an inset fed HMSA. 


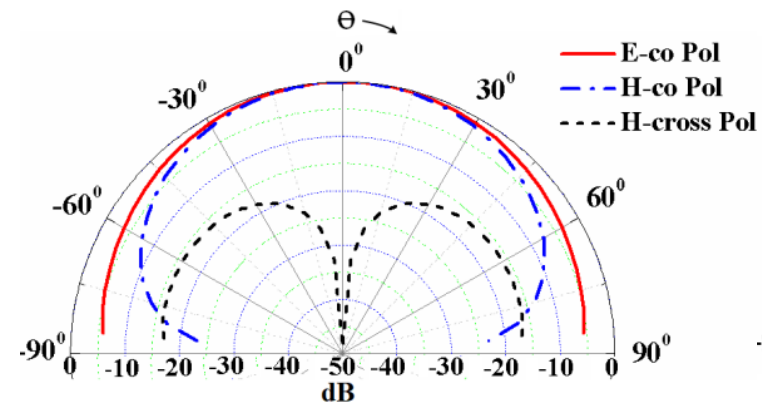

(a)

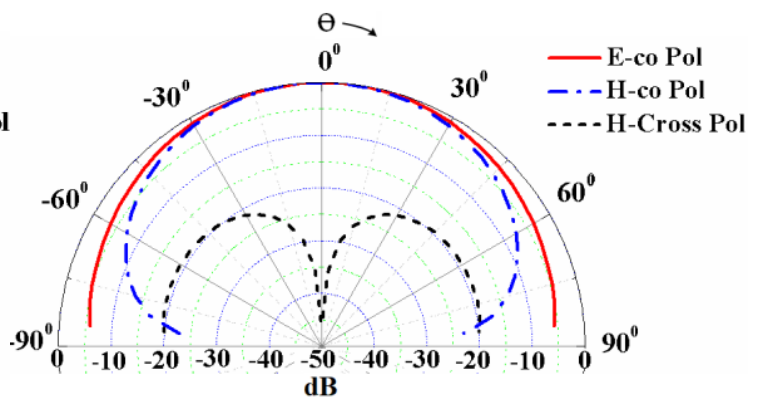

(b)

Fig.3. Simulated normalized radiation pattern of inset fed HMSA fed along (a) $Y$-axis at $1.795 \mathrm{GHz}$ and (b) $X$-axis at $1.801 \mathrm{GHz}$.

As stated earlier, the purpose of the inset notch length and width of MS-line across the HMSA is to meet the requirement of $50 \Omega$ impedance along the feed axis with that of the patch, without utilizing any extra matching element. The notch length and its respective junction capacitance influence the fundamental resonant frequency of HMSA by approximately 1-2\%. Also, in this feeding technique, the input impedance is a function of $\cos ^{2}(\pi x / S)$, and $x$ is the input feed point location measured across the radiating edge from the center [3]-[5]. Fig. 3 illustrated the increased cross-polarization level of $H$ plane, due to the inset feeding method, which disturbs the structural geometry of an antenna across $E$ plane. The $E$-plane cross-pol levels are negligibly small. Table I gives the comparison of CTCR values of conventional inset fed HMSA in $H$-plane, within the angular range of $-30^{\circ} \leq \theta \leq 30^{\circ}$ and $-60^{\circ} \leq \theta \leq$ $60^{\circ}$ where, $\theta$ is angle measured from broadside direction.

TABLE I. COMPARISON OF SIMULATED CO-POLARIZATION TO CROSS-POLARIZATION LEVELS RATIOS FOR INSET FED HMSA

\begin{tabular}{|c||c|c|c|c|}
\hline \multirow{2}{*}{\multicolumn{1}{c||}{ Configuration }} & \multicolumn{4}{|c|}{ Polarization ratio (dB)-CTCR } \\
& & \multicolumn{4}{|c|}{$\theta \in\left( \pm 30^{\circ}, \pm 60^{\circ}\right)$} \\
\cline { 2 - 5 } & $\theta=-30^{\circ}$ & $\theta=30^{\circ}$ & $\theta=-60^{\circ}$ & $\theta=60^{\circ}$ \\
\hline \hline HMSA fed at $X$-axis & 19.69 & 19.72 & 11.76 & 11.78 \\
\hline HMSA fed at $Y$-axis & 16.62 & 16.57 & 8.60 & 8.57 \\
\hline
\end{tabular}

From the Table I, it is noted that the configuration with inset feed along the $X$-axis has a lower crosspolarization level as compared to that fed along the $Y$-axis HMSA. With inset feed, both the configurations are asymmetrical, but, in the latter case of the feed at the vertex, very highly concentrated electric field gets perturbed, leading to increased asymmetry in the $E$-plane, increasing the cross-pol level, thus, a lower CTCR in $H$-plane. In higher frequency range (millimeter wave/ higher microwave range), the inset feed MS-line dimension becomes as good as that of the patch, which makes it unrealizable. It also increases the undesired radiation from the feed structure. For overcoming this problem, in this paper, a method using a single and a pair of shorting posts for directly feeding HMSAs

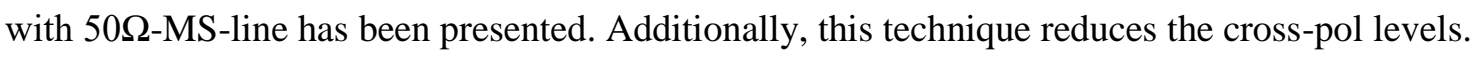




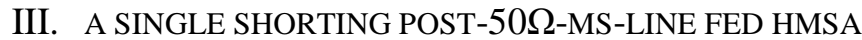

An HMSA of the side length $S$ has been designed as discussed in the previous section. Initially, to

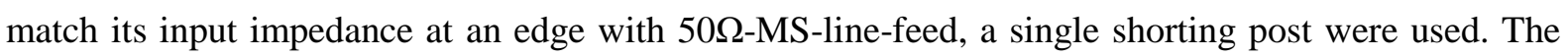
edge input impedance and the resonant frequency of various mode has been changed by loading a shorting post because it alters the field distribution into the patch. A single shorted configurations of

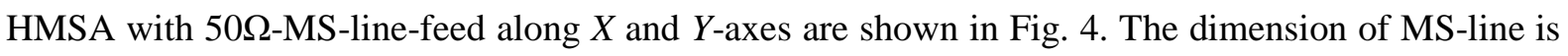
width $\left(W_{s}\right)$ equal to $4.538 \mathrm{~mm}$ and length of $10 \mathrm{~mm}$ across the input feeding point.

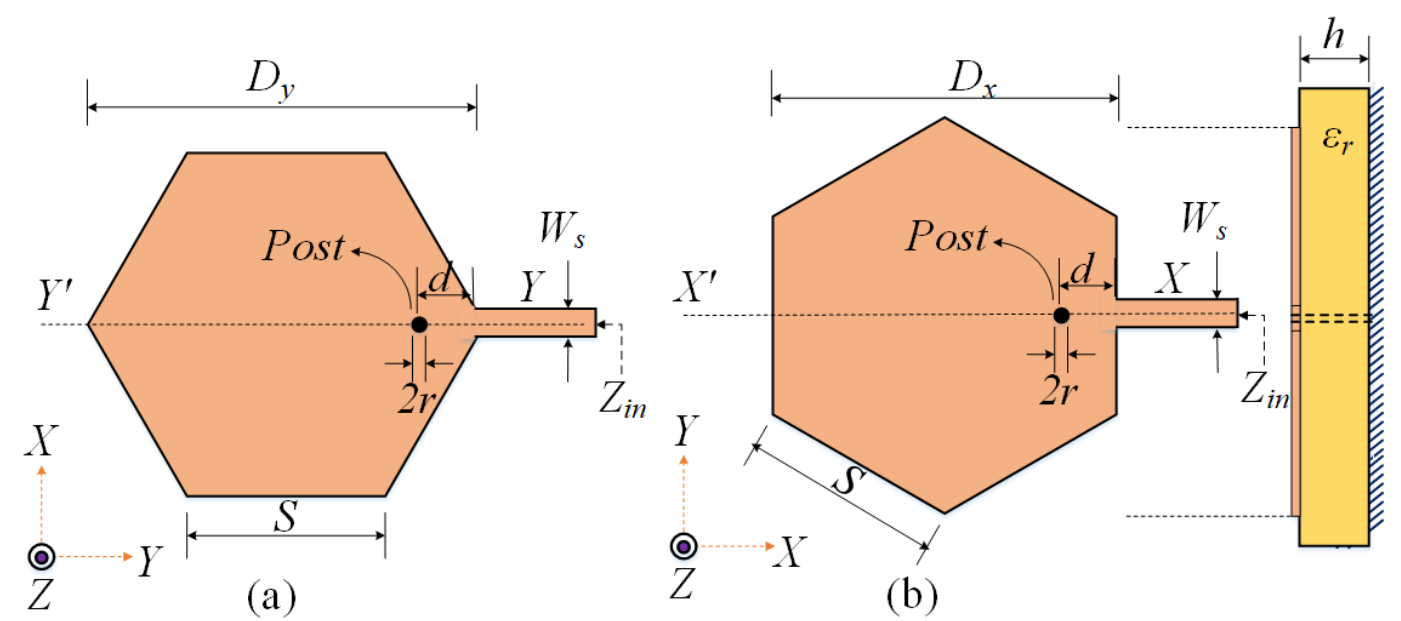

Fig 4. The geometry of a shorting post loaded HMSA (a) configuration-A (Feed along $Y$-axis) and (b) configuration-B (Feed along $X$-axis).

An effective dimension of the patch has been changed slightly with the use of shorted MS-line (without inset notch/width), which-in-turns slightly decrease the resonant frequencies of the patch. The patch centre has zero potential for the fundamental mode, which implies that by loading a shorting post at the centre of the patch, cannot change the fundamental mode frequency. Moreover, if the patch shorted at the centre, it originates another lower order mode which has a resonant frequency equal to $F_{L}$ [10]-[14]. This lower order mode frequency $F_{L}$ obtained due to quarter-wavelength, which includes the most considerable distance from the shorting post position to the diagonally opposite open end on the edge of an HMSA. When the shorting post located nearer to the edge of the HMSA, the maximum reduction in the $F_{L}$ was achieved. [2], [7].

Further study at $F_{L}$ is not incorporated in this paper. When shorting post is not at the centre of the patch, it changes the field distribution into the patch of the approximate fundamental $\mathrm{TM}_{11}$ mode and thus its frequency $F_{F}$. Concerning the density of the surface current, it has very high value at the position of shorting post and gets to be least at the open end (edge). In this way, because of this kind of refinement will eventually enlarge the $F_{F}$. When shorting post position is changing from the centre towards the edge, the edge impedance reduces and eventually becomes zero when the shorting post reaches the edge. This concept is used to locate the shorting post for the $50 \Omega$ edge impedance. For 
proposed configuration $\mathrm{A}$ and configuration $\mathrm{B}$, when the position of the single shorting post located at $d / D=0.05$ (i.e. ratio of the distance of shorting post from input edge to diameter of the HMSA), the input matching is achieved at modified fundamental mode frequency $F_{F}$. For the feed positions of the HMSA configuration B and configuration A (across the $X$ and the $Y$-axes, respectively), the fundamental mode frequency shifts to $F_{F}=2.124 \mathrm{GHz}$ and $2.107 \mathrm{GHz}$, respectively, because the shorting post modified the field distribution.

\section{A. Edge Input Impedance}

A single shorting post presented over the centre line $X X^{\prime}$, which is at location $d$ from the edge feed point, with radius $r=0.5 \mathrm{~mm}$. It is observed that when the shorting post shifts from the centre towards the periphery, the peripheral impedance reduces. This concept is used to locate the shorting post for the $50 \Omega$ peripheral impedance. The simulated input resistance $\left(R_{i n}\right)$ and reactance $\left(X_{i n}\right)$ for the configuration B with various $d / D$ ratio are showed in Fig. 5. It observed that as $d / D$ ratio reduces (shorting post position shifts from the center towards the edge), i.e. $d / D=0.5$ to 0.05 , the edge input resistance at the peripheral end with $F_{F}$ reduces from 510 to $50 \Omega$, respectively and the resonant frequency $F_{F}$ gets increment from 1.790 to $2.124 \mathrm{GHz}$. Hence, by appropriate selection of the location of a shorting post, wide extent of edge input impedance of configuration B can be realized for various frequency ranges, without utilizing any other impedance matching techniques. In this way, for configuration $\mathrm{B}$, when shorting post is positioned at $d / D=0.05$, the proper input match is realised at the modified frequency $F_{F}=2.124 \mathrm{GHz}$. Similar kind of results is achieved for configuration A, which are not presented here to avoid repetition.

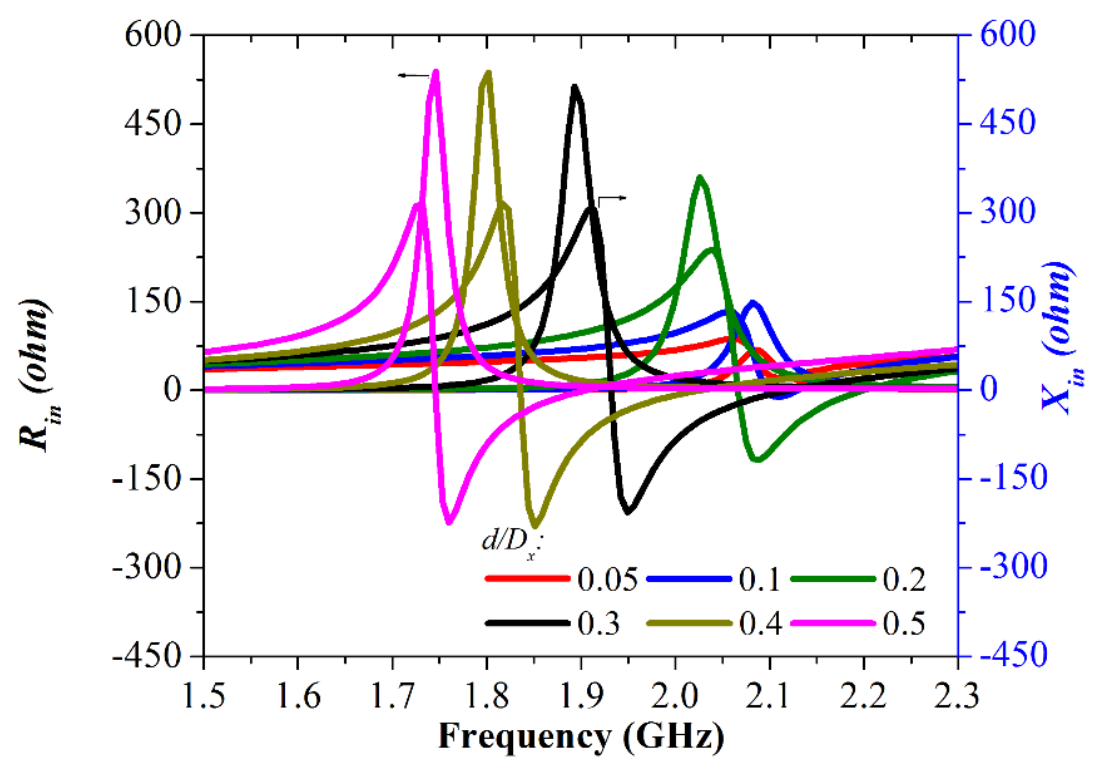

Fig. 5. Simulated input resistance and reactance at corresponding $F_{F}$ of a single shorting post loaded HMSA fed along $X$ axis (configuration B) by $50 \Omega$-MS-line. 


\section{B. Distribution of current on the surface and radiation pattern}

Fig. 6 (a) to (d) demonstrate the current distributions on the surface for a single shorted HMSAs for both the feed configuration $\mathrm{A}$ and $\mathrm{B}$ at respective frequencies $F_{F}$. For both these HMSAs with the centre shorting post, distribution of the current on the surface is similar to that of the approximate fundamental $\mathrm{TM}_{11}$ mode. As the location of the shorting post moved in the direction along the periphery, the surface current distribution begins to be progressively asymmetrical, and the fundamental mode gets changed. This kind of asymmetrical distribution of the current on the surface of the patch in the $E$-plane (Feed axis) causes enhanced cross-polarization level in the $H$-plane. Fig. 7 illustrates the comparison of simulated co-polarization levels in the E-plane and corresponding cross-polarization levels in the $H$ plane with various positions of $d / D$ ratio at corresponding modified $F_{F}$ for both the configuration A and B. It is taken note from Fig. 7 (a) and (b), that as the position of the shorting post shifts from the centre to the edge of the HMSA, the cross-polarization level in the off-boresight direction in the $H$-plane increases from -31 to $-5 \mathrm{dBi}$, and -20 to $-5 \mathrm{dBi}$ in case of configuration $\mathrm{A}$ and $\mathrm{B}$, respectively, whereas the co-polarization levels in the $E$-plane is about the same for both the cases. The proposed 50 $\Omega$-MSline-feed HMSA (Conf. A and B) remove the requirement of an individual TRL calibration kit required for $100 \Omega-M S-l i n e$ in [10] for dis-embedding the input edge impedance.

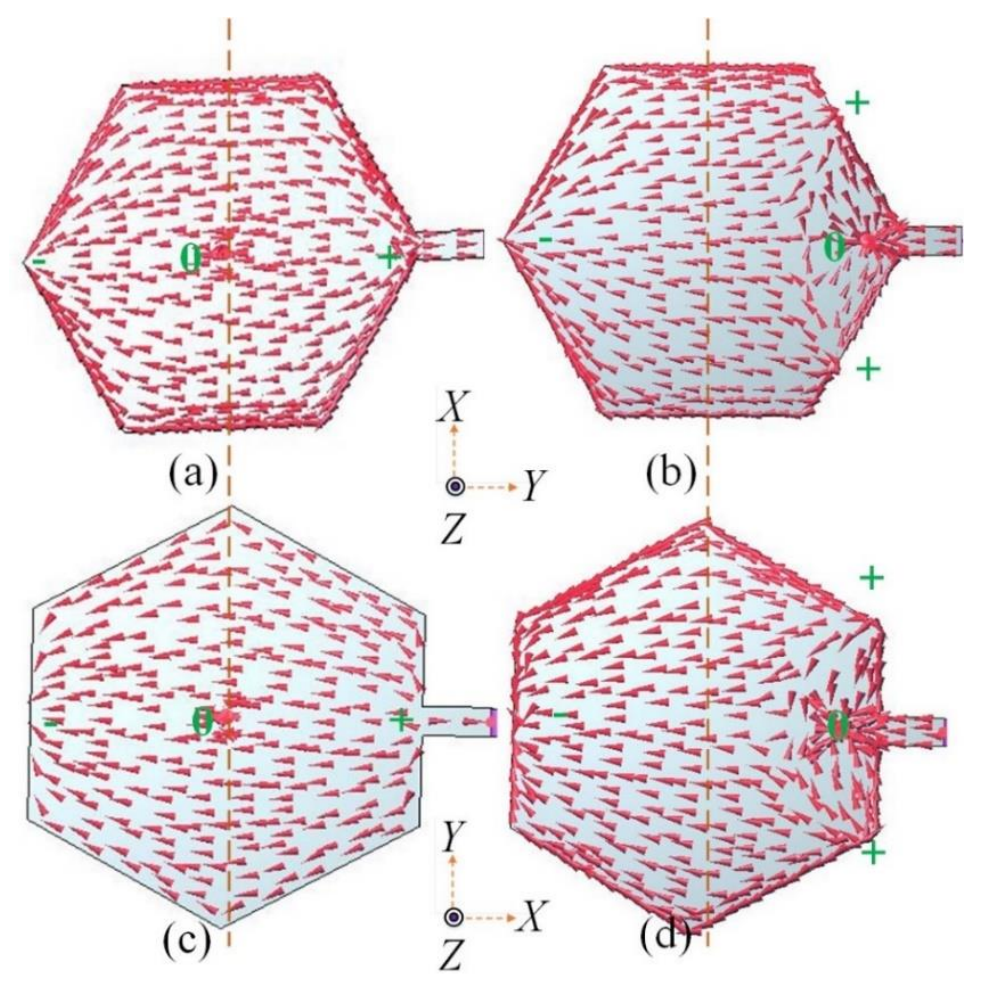

Fig.6. Current distribution on configuration A and configuration B with two shorting post positions (a) $d / D=0.5$ (fed along $Y$-axis HMSA), (b) $d / D=0.05$, (c) $d / D=0.5$ (fed along $X$-axis HMSA) and (d) $d / D=0.05$ with respective $F_{F}$. 


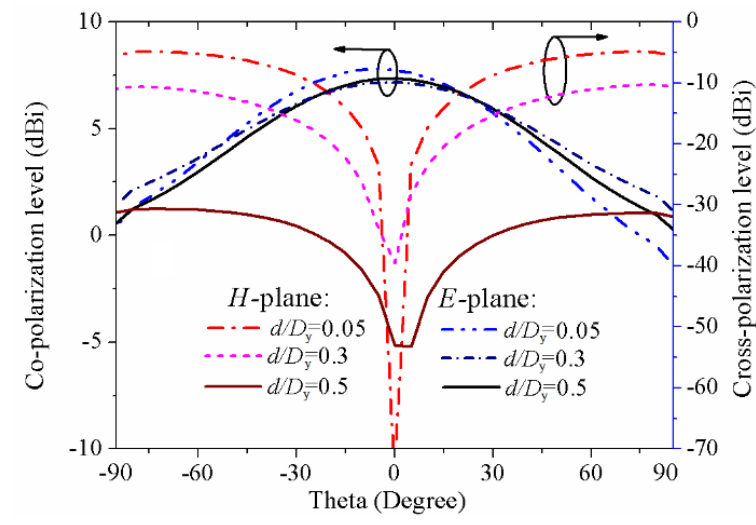

(a)

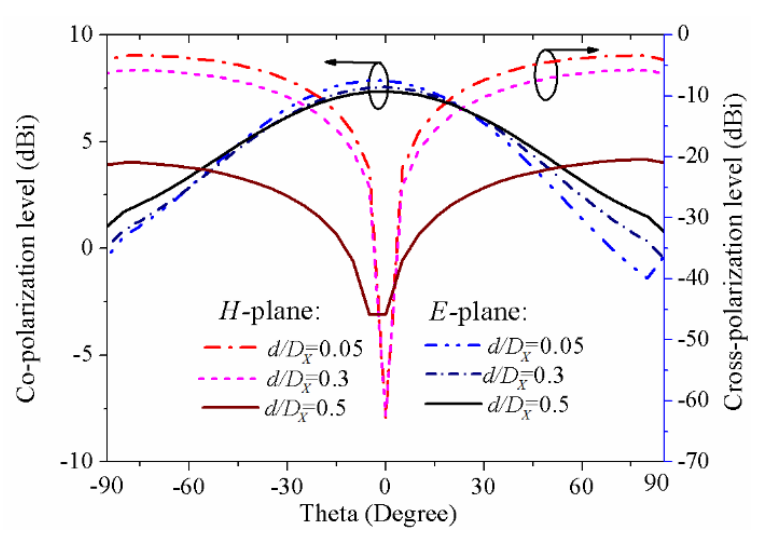

(b)

Fig.7. Simulated plot of co-polarization level in $E$-plane and cross-polarization level in $H$-plane of single shorting posts HMSA with different $d / D$ ratio (a) configuration $\mathrm{A}$ (at $d / D_{y}=0.5,0.3,0.05$ the corresponding modified frequencies are $F_{F}=$ $1.741,1.973$ and $2.107 \mathrm{GHz}$ ), (b) configuration B (at $d / D_{x}=0.5,0.3,0.05$ the corresponding modified frequencies are $F_{F}=$ $1.790,1.981$ and $2.124 \mathrm{GHz})$

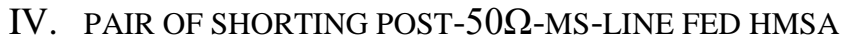

To create the configuration symmetrical across the $E$-plane (along $X X^{\prime}$ and $Y Y^{\prime}$ line of the two feed configurations of HMSAs) and therefore to reduce the cross-polarization level in $H$-plane, a pair of shorting posts method has been utilised, in this section. Proposed configuration geometry with two feed conditions are shown in Fig. 8 (a) and (b). Dimensions of the HMSA and substrate properties are kept similar to that of the earlier cases.

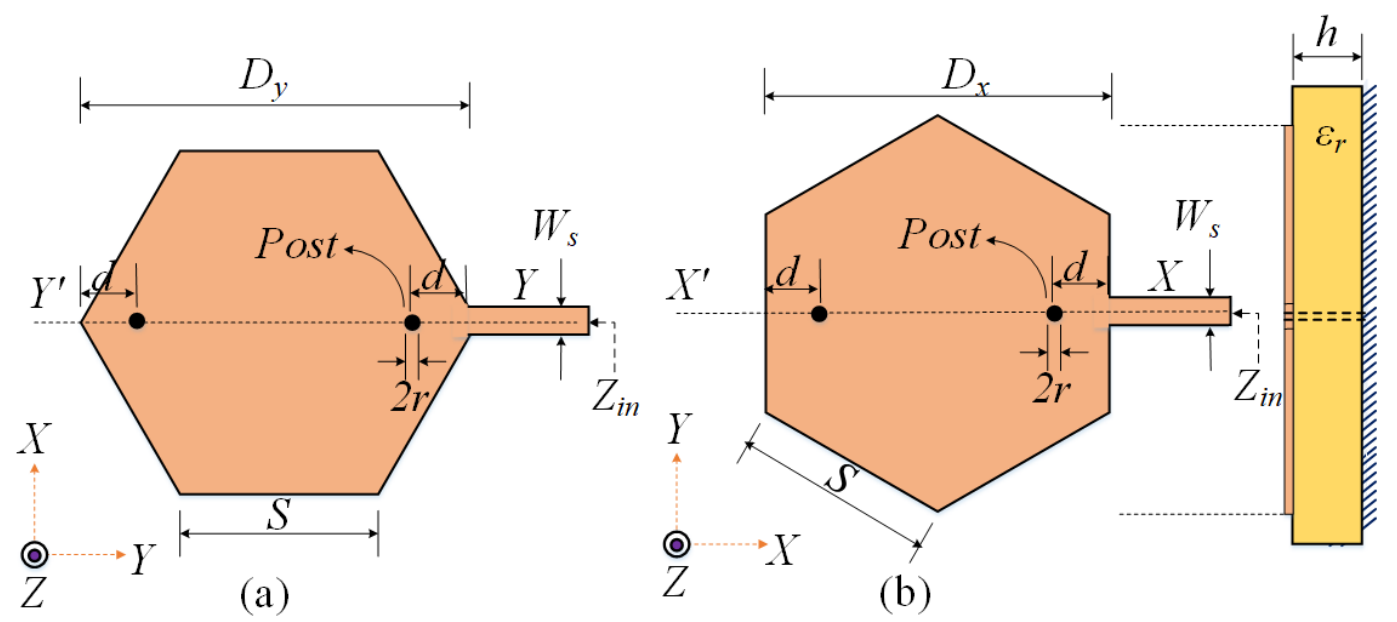

Fig. 8. (a) Geometries of a pair of shorting post loaded HMSAs (a) configuration-C ( $Y$-axis) and (b) configuration-D ( $X$ axis).

\section{A. Edge Input Impedance}

Similar to that of the case of a single shorted HMSA (Conf. A and B), the resonant frequency of lower order mode $F_{L}$ gets excited in Conf. $\mathrm{C}$ and $\mathrm{D}$ as well, besides modifying the fundamental mode with 
frequency $F_{F}$. The investigation has been reported in this section is with respect to that of the modified fundamental mode frequency $F_{F}$ only. Fig. 9 shows the simulated input resistance $\left(R_{i n}\right)$ and reactance $\left(X_{i n}\right)$ for various $d / D$ ratios of the pair of shorting posts HMSA fed along the $X$-axis (configuration $\mathrm{D}$ ). It noticed that as the shorting post position $d / D$ ratio decreases, i.e. $d / D=0.5$ to 0.05 , the edge input impedance at $F_{F}$ reduces from 510 to $50 \Omega$, while the corresponding resonant frequency $F_{F}$ gets increased from 1.790 to $2.425 \mathrm{GHz}$. Two shorting post position on the patch changes the surface current distribution, whose surface current density is highest at the location of shorting post. The half cycle surface current distribution gets slightly shortened leading to slight increase in the fundamental mode frequency $F_{F}$. Proper matching for configuration D is obtained at $F_{F}$ for $d / D=0.05$. Similarly, edge input impedance was optimised for the configuration $\mathrm{C}$.

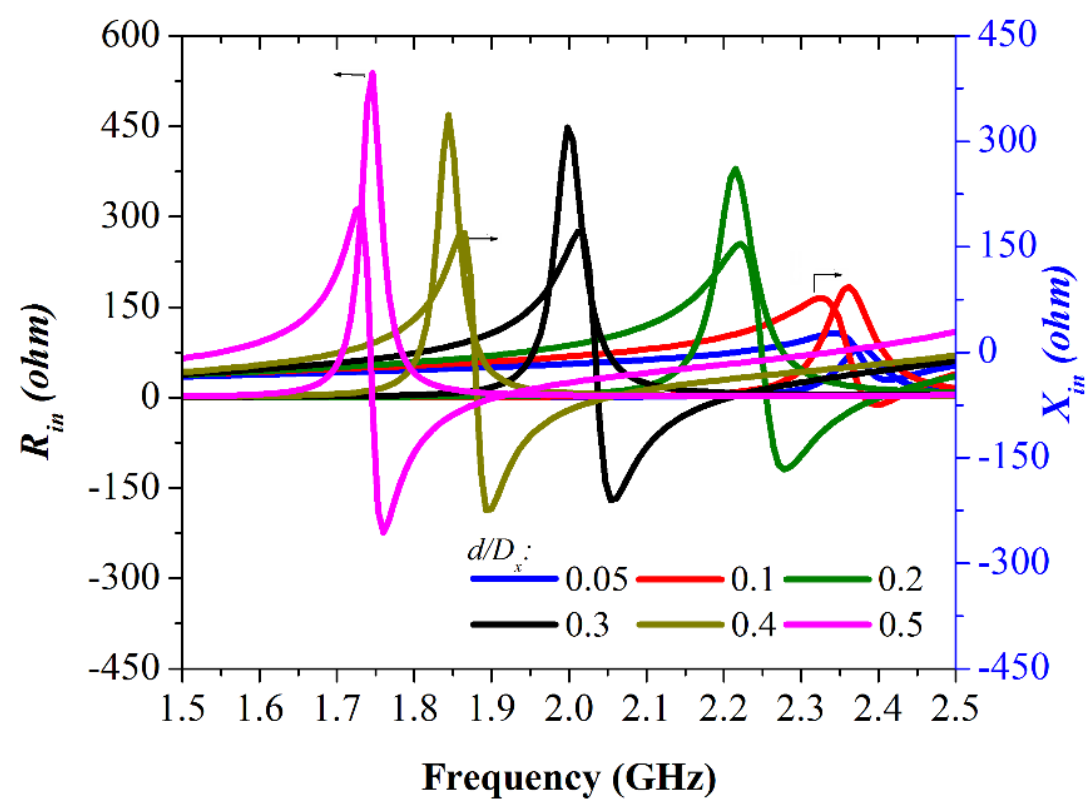

Fig. 9. Simulated input resistance and reactance at corresponding modified fundamental frequency $F_{F}$ of configuration D.

\section{B. Distribution of current on the surface and radiation pattern}

Fig. 10 illustrated the current distribution on the surface of the proposed configurations $\mathrm{C}$ and $\mathrm{D}$ for two cases of the position of the pair of shorting posts at corresponding frequency $F_{F}$. It is observed that current distribution is nearly symmetrical along the feed centerline for both the configurations. Fig. 11 (a) and (b) depicts the co-polarization level in $E$-plane and cross-polarization level in $H$-plane for both the HMSA configuration $\mathrm{C}$ and $\mathrm{D}$ with three cases of shorting post position $(d / D)$. There is a substantial reduction of cross-polarization level in the $H$-plane as compared to that of a corresponding case of single shorting post loaded HMSA configurations as illustrated in Fig. 7 (a) and (b). The improvement is more than $15 \mathrm{~dB}$ for all the position of $d / D$. The $E$-plane co-pol levels are similar for all the positions of shorting posts. For the HMSA, operating at fundamental mode frequency $F_{F}$ (which gets modified in 
the presence of shorting post) the direction of the electric field vector remains the same, when the shorting post is used. Therefore, the polarization remains unaltered.

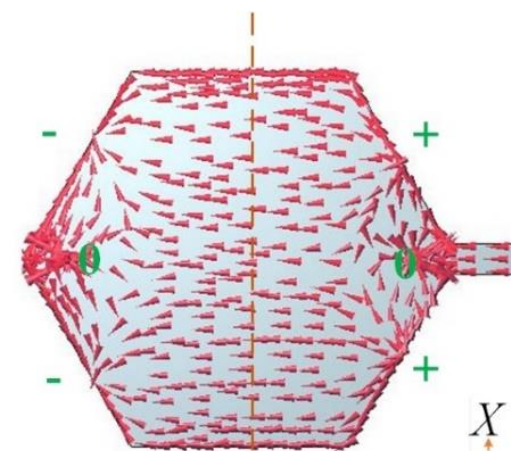

(a)!

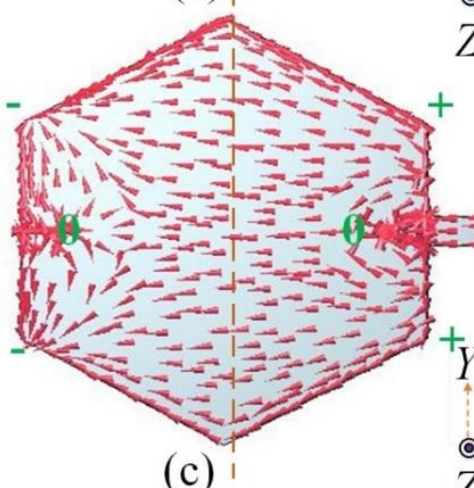

(c)

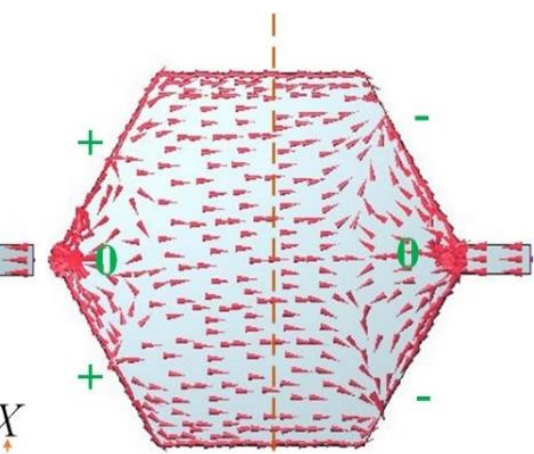

(b)

$\odot \ldots Y$

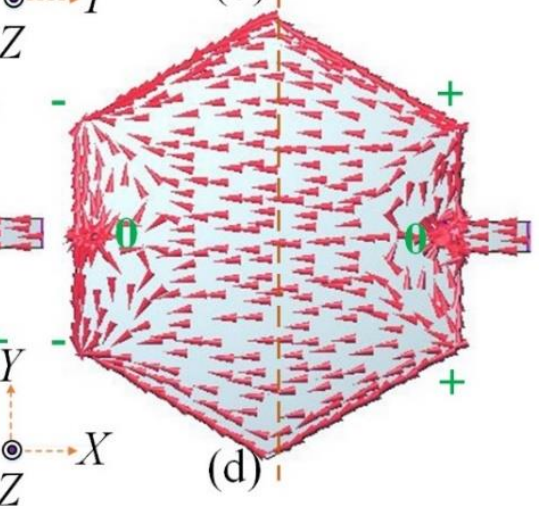

Fig.10. Surface current distribution of a pair of shorts loaded HMSA for both the feed configurations with two shorting positions a) $d / D=0.1$, (b) $d / D=0.05$ for configuration $\mathrm{C}$ and (c) $d / D=0.1$, (d) $d / D=0.05$ configuration $\mathrm{D}$ with corresponding $F_{F}$.

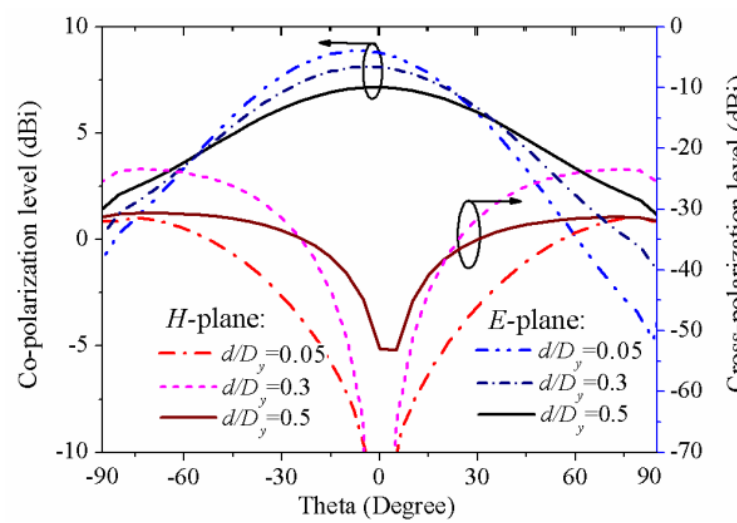

(a)

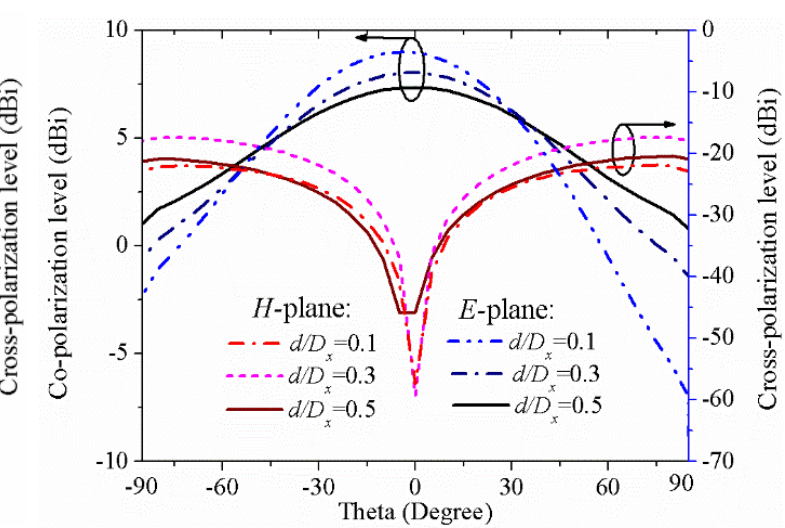

(b)

Fig.11. Simulated plot of co-polarization level in $E$-plane and cross-polarization level in $H$-plane of a pair of shorting posts loaded HMSA with different $d / D$ ratio. (a) Configuration $\mathrm{C}$ (at $d / D_{y}=0.5,0.3,0.05$ for the corresponding frequencies of $F_{F}$ $=1.741,2.053$ and $2.404 \mathrm{GHz}$ ), (b) configuration $\mathrm{D}$ (at $d / D_{x}=0.5,0.3,0.05$ for the corresponding frequencies of $F_{F}=1.790$,

$$
2.074 \text { and } 2.425 \mathrm{GHz} \text { ) }
$$


For the centre shorting position $(d / D=0.5)$, the frequency $F_{F}$, input resistance and the directivity remain similar as that of a single shorting post HMSA, which in turn are similar as conventional HMSA, as they represent the same case. However, due to improved symmetry in current distribution on the surface of shorted HMSA with a pair of shorting post for all the values of $d / D$, the cross-polarization levels decrease, resulting in an improvement in the directivity $\left(D_{\mathrm{r}}\right)$. The increase in the value of the directivity for the configuration $\mathrm{D}$ is $1.14 \mathrm{~dB}$ for the case of $d / D=0.05$ in comparison with that of the corresponding single shorted HMSA (Configuration B). Fig. 12 shows the performance of the pair of shorting post loaded HMSA fed along the $X$-axis. For most of the cases of $d / D$, the value of directivity of the pair of shorted HMSA is higher than that of a single shorting post loaded HMSA. A similar response observed for the configuration $\mathrm{C}$ (HMSA fed along the $Y$-axis).

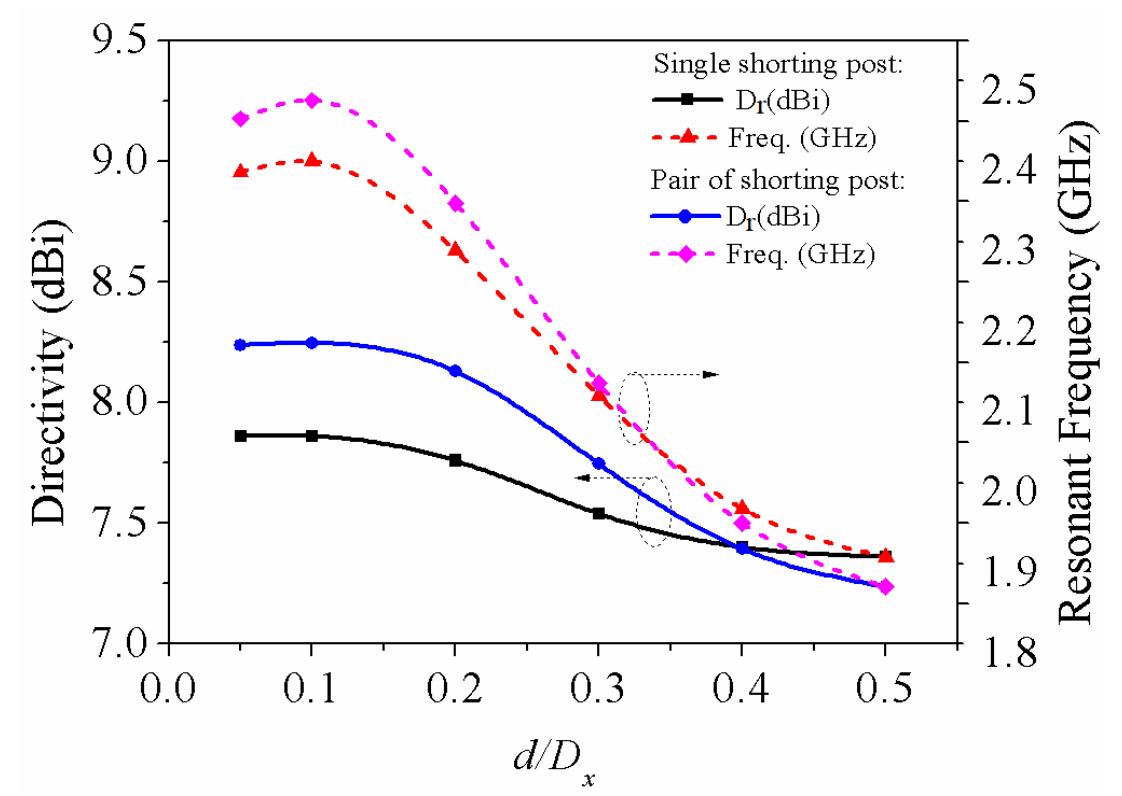

Fig. 12. Performance comparison of configuration B and configuration D (HMSAs fed along $X$-axis) for various values of shorting post position $d / D$ ratio on directivity and resonant frequency.

\section{EXPERIMENTAL VERIFICATIONS AND DISCUSSIONS}

Proposed shorted HMSAs (i.e. Configuration A to configuration D) have been manufactured on Arlon substrate with $\varepsilon_{r}=2.5, h=1.59 \mathrm{~mm}$ and $\tan \delta=0.003$ and testing have been performed to demonstrate their utility. The radius equal to $0.5 \mathrm{~mm}$ is used for all the shorting posts, which were position at $d / D=$ 0.05 for all the proposed configurations. The $50 \Omega$-MS-line has dimension as $W_{s}=4.538 \mathrm{~mm}$ and length= $10 \mathrm{~mm}$, which soldered at the end with SMA connector. The dimension of the ground plane for proposed shorted HMSAs fed along $X$-axis (configuration B or D) and $Y$-axis (configuration A or C) are $77 \times 77$ $\mathrm{mm}^{2}$ and $85 \times 85 \mathrm{~mm}^{2}$, respectively. Photographs of shorted HMSAs are depicted in Fig. 13 (a). AgilentFieldfox made Vector Network Analyzer (VNA-N9917A) is used in the antenna measurements. For 
radiation pattern measurement for a transmitting antenna, a horn antenna was utilised, that is positioned in its far-field distance as depicted in Fig. 13 (b).

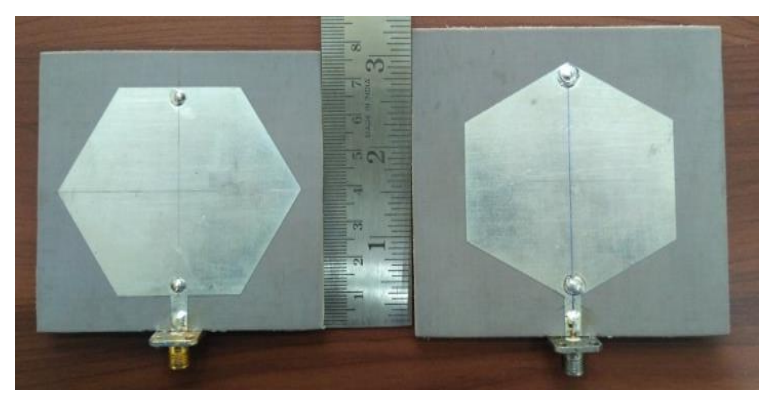

(a)

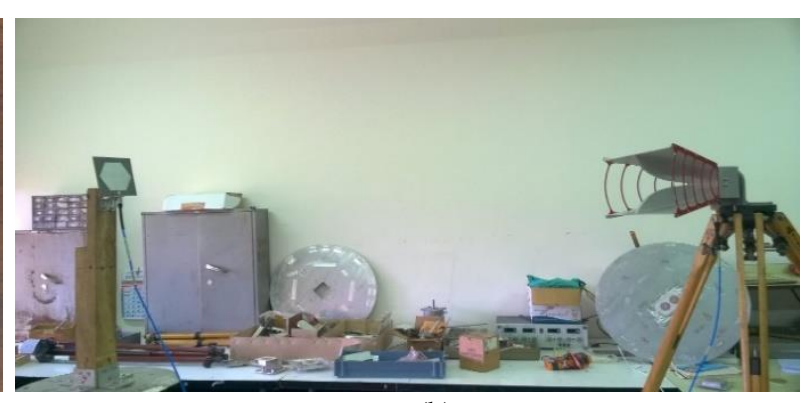

(b)

Fig.13. (a) Photographs of proposed configurations D and C with the pair of shorting post loaded HMSAs at $d / D=0.05$ and (b) experimental setup.

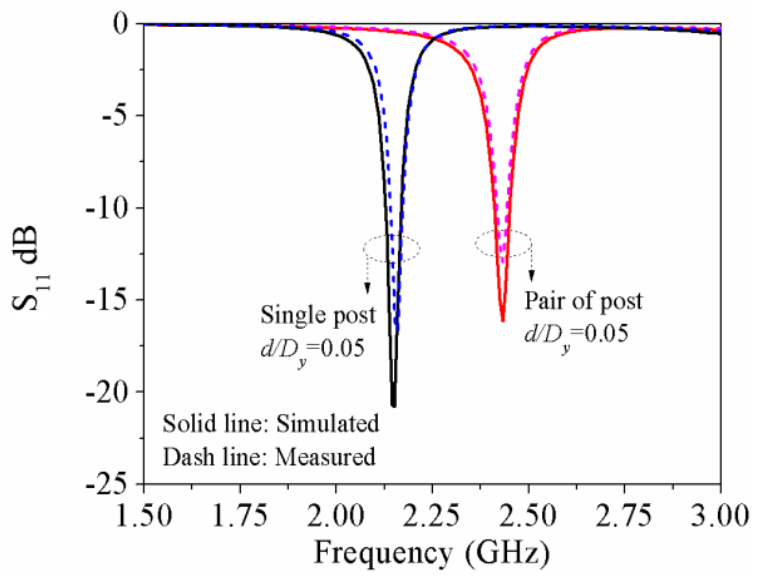

(a)

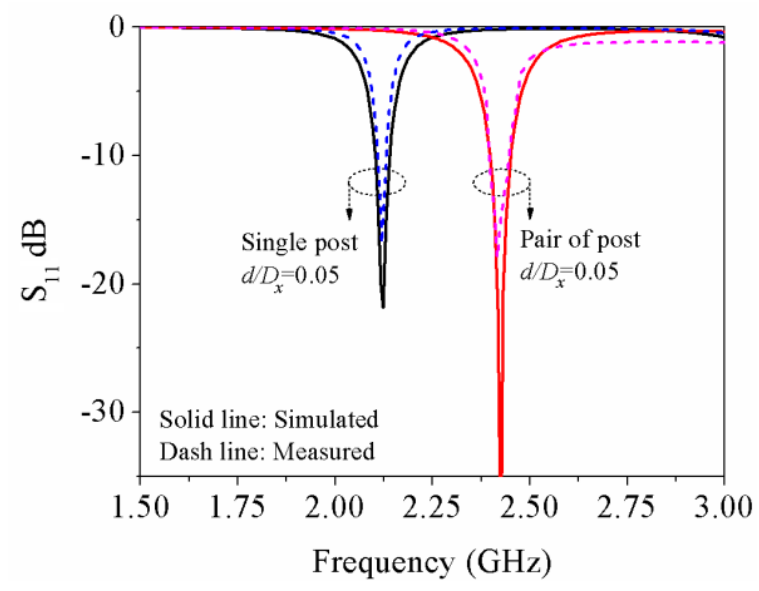

(b)

Fig.14. Simulated and measured $S_{11}$ for a proposed shorted post loaded HMSAs (a) Configuration A and C (with feed along $Y$-axis) and (b) configuration B and $\mathrm{D}$ (with feed along $X$-axis).

The simulated and measured return loss for both the proposed antenna configurations with respective single and a pair of shorting posts are compared in Fig. 14 (a) and (b). The HMSA configuration without loading a shorting post has large edge input impedance, which essentially does not get matched with $50 \Omega$-MS-line-feed. By using a single and the pair of shorting posts, the input impedance is nearly equal to $50 \Omega$, making a good input matching. The configuration A (HMSA fed across the $Y$-axis), has simulated and measured modified $F_{F}$ of $2.107 \mathrm{GHz}$ and $2.113 \mathrm{GHz}$, respectively with $\%$ bandwidth (BW) of 1 and 0.95 . Similarly, for the configuration $\mathrm{C}$, the simulated $F_{F}$ is $2.404 \mathrm{GHz}$ against the measured value of $2.400 \mathrm{GHz}$, with \% BW of 1 and 0.92 , respectively. In the case of configuration B (HMSA fed along $X$-axis) has simulated and measured $F_{F}$ of $2.124 \mathrm{GHz}$ and $2.121 \mathrm{GHz}$ respectively, with $\% \mathrm{BW}$ of 1 and 0.97 . Similarly, for configuration $\mathrm{D}$, the simulated modified $F_{F}$ is $2.425 \mathrm{GHz}$ 
against the measured value of $2.423 \mathrm{GHz}$, with $\% \mathrm{BW}$ of 1 and 0.94 , respectively. The HMSAs with feed along the $Y$-axis has a lower resonant frequency for both the shorting conditions than that of similar configurations, which are fed along the $X$-axis because they have slightly longer resonant length.

Fig. 15 demonstrates the block diagram of the radiation pattern measurement setup. In the antenna pattern measurement system, for transmitting antenna, a dual-ridge waveguide horn antenna was used, while antenna under test (AUT) work as a receiving antenna. The transmitting antenna is position at a far-field distance $(\mathrm{R})$ of more than $1 \mathrm{~m}$ from AUT. Two ports of a VNA has been used with low loss high-frequency RF cables to connect AUT and transmitting antenna. VNA interfaced with a personal computer using LAN cable for the measurement of transmission coefficient $S_{21}$. The gain of the AUT is calculated using the Friis equation by taking losses into account [2]-[3].

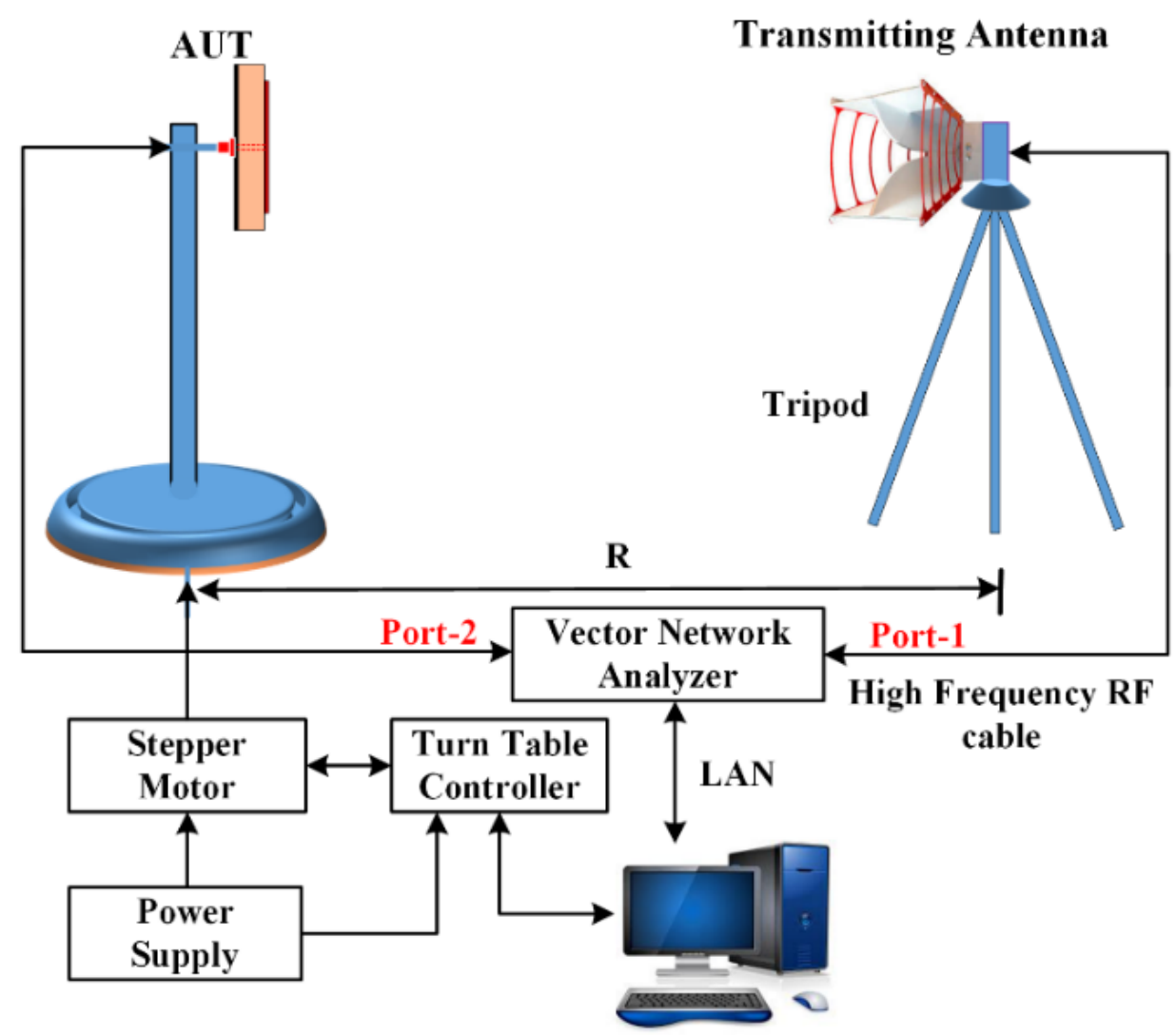

Fig. 15. Schematic diagram of the radiation pattern measurement set-up.

In case of the conventional HMSA, the inset feed technique introduces a physical asymmetry along the $E$-plane, that in turn, slightly tilts the main beam of the radiation pattern the $H$-plane by maximum up to $10^{\circ}$. While in case of both the proposed shorted HMSA configurations, the maximum radiation is in the broadside direction. The comparison of simulated and measured radiation patterns in both the principal planes ( $E$ - and $H$-plane) for all the shorted HMSA configurations are examined in Fig. 16 and Figs. 17, respectively at corresponding $F_{F}$. The simulated and measured HPBWs for all the configurations are summarised in Table II. 


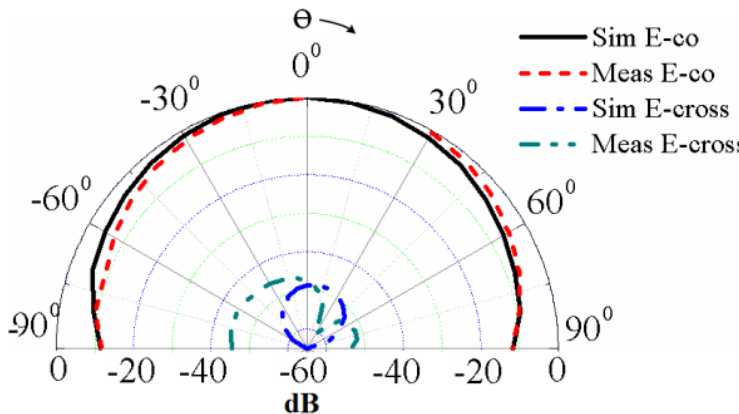

(a)

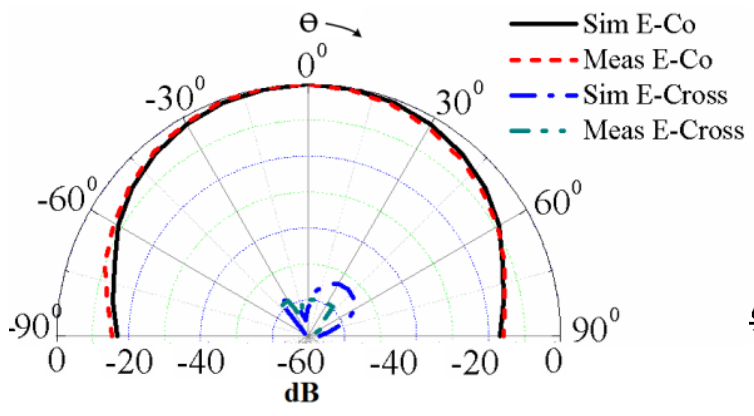

(c)

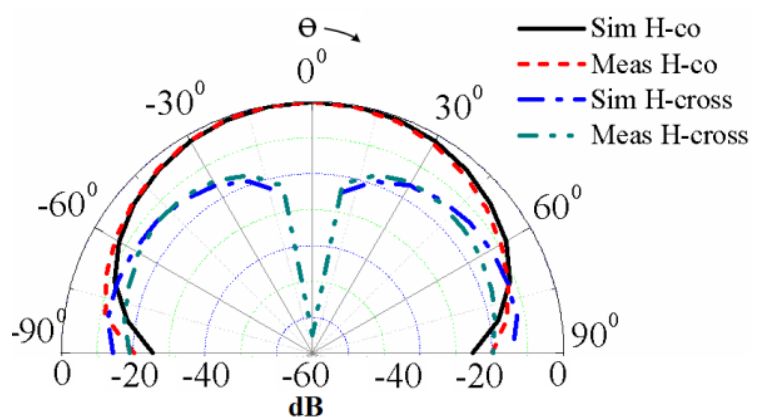

(b)

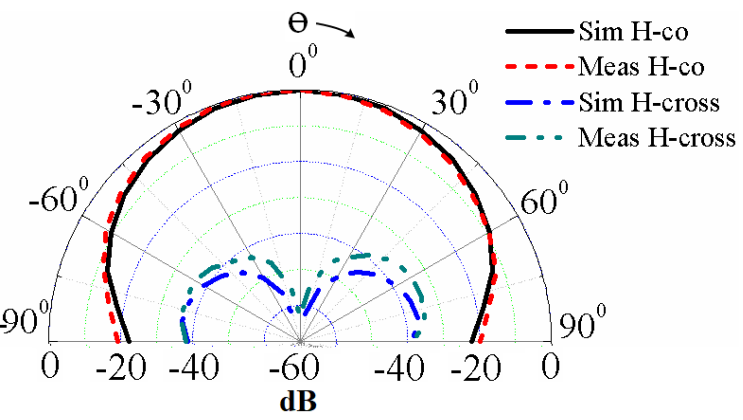

(d)

Fig.16. (a) Simulated and measured radiation pattern of configuration A at $2.113 \mathrm{GHz}$ (a) $E$-plane and (b) $H$-plane, and configuration C, at $2.400 \mathrm{GHz}$ (c) $E$-plane and (d) $H$-plane.

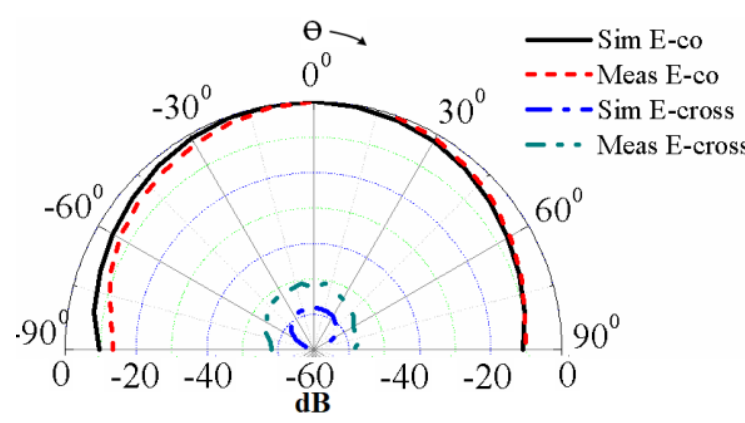

(a)

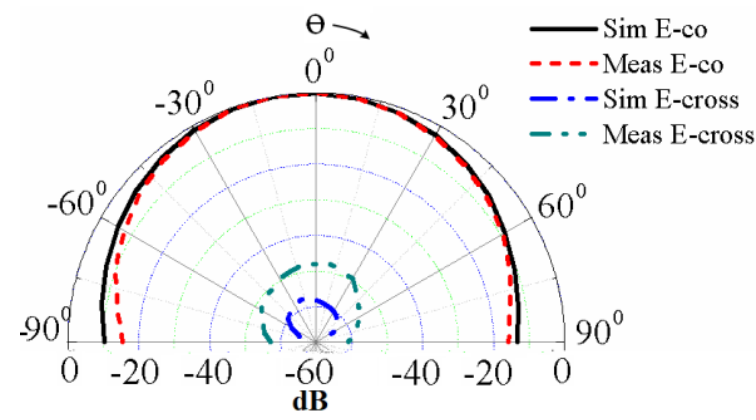

(c)

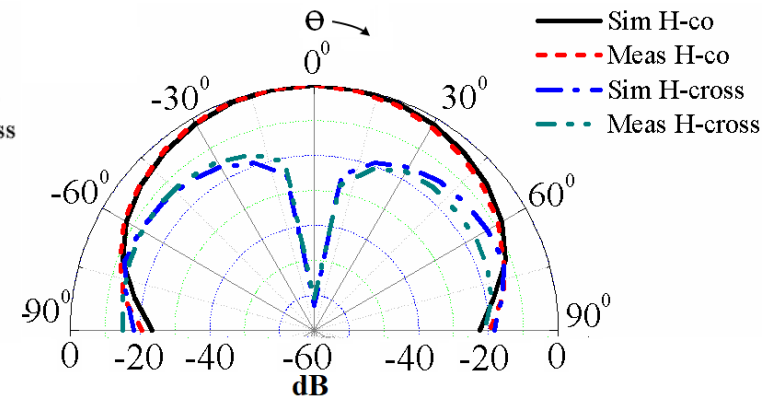

(b)

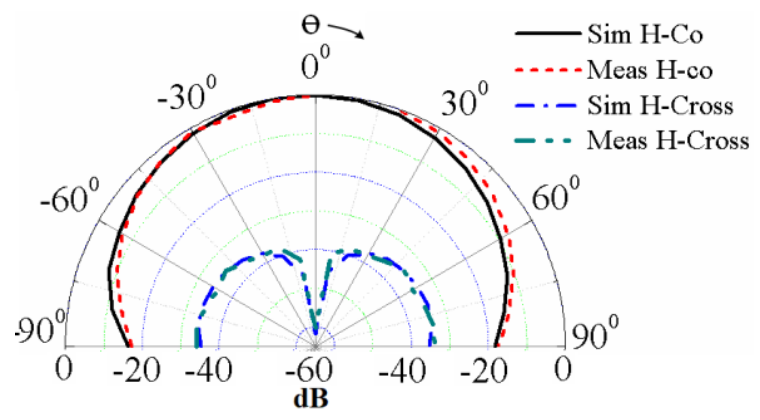

(d)

Fig.17. (a) Simulated and measured radiation pattern of configuration B at $2.121 \mathrm{GHz}$ (a) $E$-plane and (b) $H$-plane and configuration D at $2.423 \mathrm{GHz}$ (c) $E$-plane and (d) $H$-plane. 
TABLE II. COMPARISON OF SIMULATED AND MEASURED HPBW

\begin{tabular}{|c||c|c|c|c|}
\hline \multirow{2}{*}{$\begin{array}{c}\text { Configuration } \\
(d / D=0.05)\end{array}$} & \multicolumn{2}{c|}{$E$-plane HPBWs } & \multicolumn{2}{c|}{$H$-plane HPBWs } \\
\cline { 2 - 5 } & Simulated & Measured & Simulated & Measured \\
\hline \hline Configuration C & $72^{\circ}$ & $71^{\circ}$ & $38^{\circ}$ & $34^{\circ}$ \\
\hline Configuration A & $84^{\circ}$ & $82^{\circ}$ & $44^{\circ}$ & $41^{\circ}$ \\
\hline Configuration D & $75^{\circ}$ & $73^{\circ}$ & $42^{\circ}$ & $40^{\circ}$ \\
\hline Configuration B & $86^{\circ}$ & $82^{\circ}$ & $46^{\circ}$ & $43^{\circ}$ \\
\hline
\end{tabular}

In the broadside direction, the simulated and measured cross-polarization levels in $E$-plane of both the HMSAs are less than $-40 \mathrm{~dB}$. The simulated and measured values of the CTCRs of a single and the pair

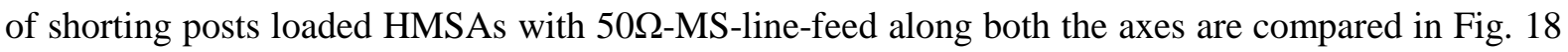
over the full angular range of $-90^{\circ} \leq \theta \leq 90^{\circ}$. Further, Table III gives the more specific comparison of CTCR values for both the HMSAs in $H$-plane, within the angular range of $-30^{\circ} \leq \theta \leq 30^{\circ}$ and $-60^{\circ} \leq \theta$ $\leq 60^{\circ}$. In case of the symmetrical pair of shorting post HMSA (configuration C and D), the crosspolarization levels are much suppressed. The CTCR values in the $H$-plane of the pair of shorting posts loaded HMSAs is at least $20 \mathrm{~dB}$ better than that of a single shorting post HMSA for both the angular ranges (configuration A and B). This is a notable improvement in the value of CTCR as compared to that obtained from the inset fed HMSA as listed in Table I, as well as RMSA as reported in [10-11]. Among the two shorted HMSAs with the pair of shorting posts, the configuration which is fed along the $Y$-axis (Configuration C) has more suppression of CTCR as compared to that fed along the $X$-axis (Configuration D), because of improved transition at vertex feed and improved symmetry.

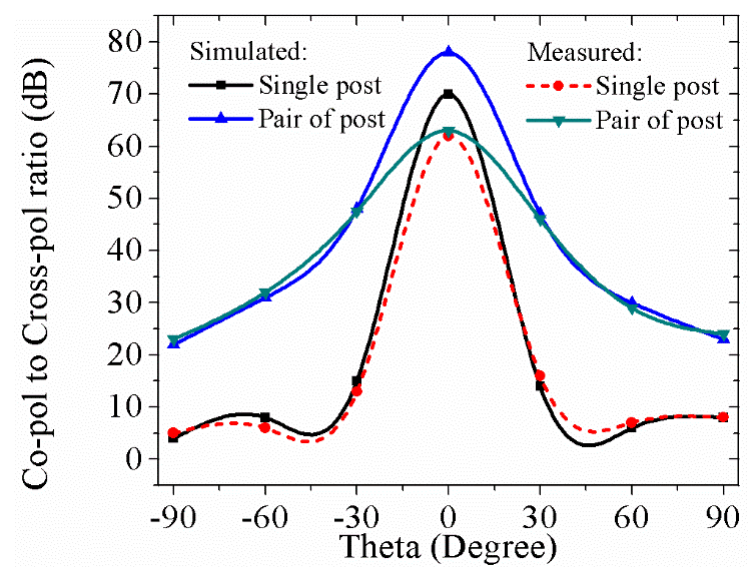

(a)

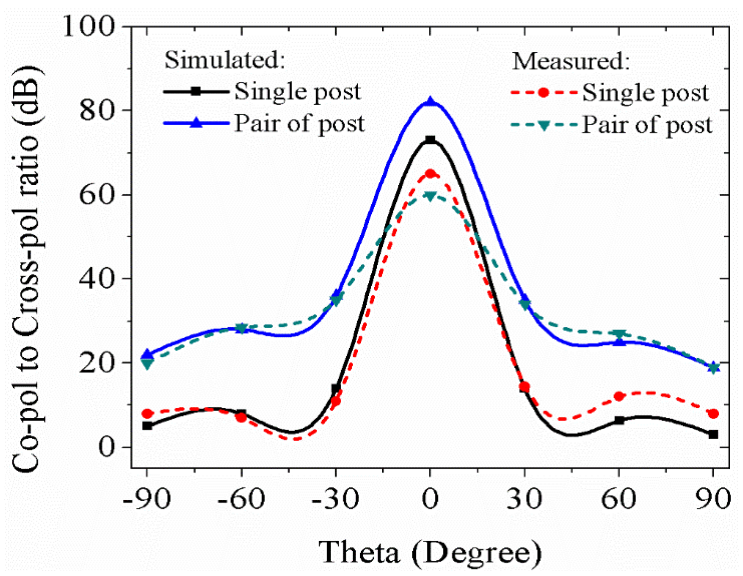

(b)

Fig. 18. Simulated and measured CTCR in the $H$-Plane of a single and the pair of shorting posts loaded HMSAs fed along (a) the $Y$-axis (configuration $\mathrm{A}$ and $\mathrm{C}$ ), and (b) the $X$-axis (configuration $\mathrm{B}$ and $\mathrm{D}$ ). 
TABLE III. COMPARISON OF SIMULATED AND MEASURED POLARIZATION RATIOS

\begin{tabular}{|c||c|c|c|c|}
\hline \multirow{2}{*}{$\begin{array}{c}\text { Configuration } \\
(d / D=0.05)\end{array}$} & \multicolumn{2}{c|}{$\begin{array}{c}\text { Polarization ratio }(\mathrm{dB}) \\
\Theta \epsilon\left(-30^{\circ}, 30^{\circ}\right)\end{array}$} & \multicolumn{2}{c|}{$\begin{array}{c}\text { Polarization ratio }(\mathrm{dB}) \\
\Theta \epsilon\left(-60^{\circ}, 60^{\circ}\right)\end{array}$} \\
\cline { 2 - 5 } & Simulated & Measured & Simulated & Measured \\
\hline \hline Configuration C & 35 & 34 & 27 & 26 \\
\hline Configuration A & 14 & 13 & 7 & 9 \\
\hline Configuration D & 47 & 46 & 30 & 31 \\
\hline Configuration B & 16 & 14 & 8 & 6 \\
\hline
\end{tabular}

\section{CONCLUSION}

An HMSA has a high edge/vertex input impedance, which causes difficulty in directly feeding it with $50 \Omega$-MS-line. A suitable position of shorting posts on the patch decreases the input impedance of the

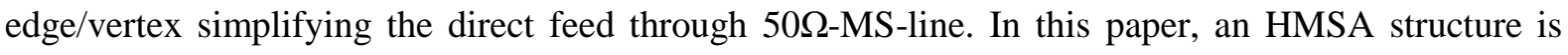
directly fed by a $50 \Omega$-MS-line with the help of a single and the pair of shorting posts. The drawback of the quarter wave transformer line and inset feed is overcome by utilizing direct MS-line feed technique, which makes the HMSA geometry symmetrical. By suitably positioning the shorting post, the peripheral edge impedance of the HMSA is varied in large range. A detailed study of the modified fundamental mode of an HMSA fed directly by $50 \Omega$-MS-line has been carried out. Simulated results of all the proposed configurations are in agreement with measured results. The CTCR values of the pair of shorting posts HMSA have more than $20 \mathrm{~dB}$ improvement as compared to that of a single shorting post loaded HMSA. The proposed impedance matching technique facilitate direct integration of antenna with microwave circuits or active devices on the same plane. It also finds applications in series or corporate fed antenna arrays design with HMSA elements. With suitable scaling factor, the proposed technique can be adapted to any frequency for various applications.

\section{ACKNOWLEDGEMENT}

The authors would like to thanks S. S. Kakatkar, J. Prajapatee and P. Irpache from Atmospheric and Microwave System Division (ATMS)-Society for Applied Microwave Electronics Engineering and Research (SAMEER), Mumbai and V. Dhavane from VJTI, Mumbai for their guidance in antenna fabrications and valuable input during the experimental measurement. The authors would also want to acknowledge SAMEER management and the TEQIP-III of VJTI-Mumbai for their financial assistance.

\section{REFERENCES}

[1] Kin-Lu Wong, Compact and Broadband Microstrip Antennas, John Wiley \& Sons, Inc., New York, USA, 2002.

[2] G. Kumar and K. P. Ray, Broadband Microstrip Antennas, Norwood, MA, Artech House, USA, 2003.

[3] C. A. Balanis, Antenna Theory: Analysis and Design, Third Edition, New York, John Wiley and Sons, Inc., 2005. 
DOI: http://dx.doi.org/10.1590/2179-10742019v18i21436

[4] L. I. Basilio, M. A. Khayat, J. T. Williams, and S. A. Long, "The Dependence of the Input Impedance on Feed Position of Probe and Microstrip Line-Fed Patch Antennas," IEEE Trans. Antennas and Propag., vol. 49, no. 1, pp. 45-47, Jan. 2001.

[5] Y. Hu, D. R. Jackson, J. T. Williams, S. A. Long, and V. R. Komanduri, "Characterization of the Input Impedance of the Inset-fed Rectangular Microstrip Antenna,” IEEE Trans. Antennas and Propag., vol. 56, no. 10, pp. 3314-3318, Oct. 2008.

[6] D. Schaubert, F. Farrar, A. Sindoris and S. Hayes, "Microstrip Antennas with Frequency Agility and Polarization Diversity," IEEE Trans. Antennas and Propag., vol. 29, no. 1, 118-123, Jan 1981.

[7] K. P. Ray, "Broadband, Dual Frequency and Compact Microstrip Antennas", PhD thesis, Indian Institute of Technology, Bombay, India, 1999.

[8] S. Bhardwaj and Y Rahmat-Samii, "Revisiting the Generation of Cross Polarization in Rectangular Patch Antennas: A Near-Field Approach", IEEE Antennas and Propag. Mag, vol. 56, no. 1, pp. 14-38, Feb 2014.

[9] J. S. Row, “A Simple Impedance-Matching Technique for Patch Antennas Fed by Coplanar Microstrip Line,” IEEE Trans. Antennas and Propag., vol. 53, no. 10, pp. 3389-3391, Oct 2005.

[10] X. Zhang and L. Zhu, "Patch Antennas with Loading of a Pair of Shorting Pins Toward Flexible Impedance Matching and Low Cross-Polarization,” IEEE Trans. Antennas and Propag., vol. 64, no. 4, pp. 1226-1233, 2016.

[11] S. M. Rathod, R. N. Awale and K. P. Ray, "Analysis of a single shorted rectangular microstrip antenna for $50 \Omega$ microstrip line feed," 2016 International Symposium on Antennas and Propagation (APSYM), Cochin,2016, pp. 1-4.

[12] S. M. Rathod, R. N. Awale, and K. P. Ray, "Shorted Circular Microstrip Antennas for $50 \Omega$ Microstrip Line Feed with Very Low Cross-Polarization,” Progress In Electromagnetics Research Letters, vol. 74, pp.91-98, 2018.

[13] A. Chapari, A. Zeidaabadi Nezhad and Z. H. Firouzeh, "Analytical Approach for Compact Shorting Pin Circular Patch Antenna," IET Microwaves Antennas Propag., vol. 11, no. 11, pp.1603-1608, 2017.

[14] A. A. Deshmukh, S. Pawar, P. Kadam, A. Odhekar and K. P. Ray, "Analysis of single shorted square microstrip antenna," 2017 International Conference on Emerging Trends \& Innovation in ICT (ICEI), Pune, 2017, pp. 123-128.

[15] S. Samanta, P. S. Reddy and K. Mandal, "Cross-Polarization Suppression in Probe-Fed Circular Patch Antenna Using Two Circular Clusters of Shorting Pins,” IEEE Trans. Antennas and Propag., vol. 66, no. 6, pp. 3177-3182, June 2018.

[16] N. Liu, L. Zhu, G. Fu and Y. Liu, “A Low Profile Shorted-Patch Antenna With Enhanced Bandwidth and Reduced HPlane Cross-Polarization,” IEEE Trans. Antennas and Propag., vol. 66, no. 10, pp. 5602-5607, Oct. 2018.

[17] K. P. Ray and M. D. Pandey, "Resonance Frequency of Hexagonal and Half-hexagonal Microstrip Antennas," Microw. Opt. Technol. Lett., vol. 51, no. 2, pp. 448-452, 2009.

[18] HyperLynx 3D EM Design System, Mentor Graphics Corp, Ver. 15.2, Wilsonville, USA, 2012.

Brazilian Microwave and Optoelectronics Society-SBMO Brazilian Society of Electromagnetism-SBMag received 18 Aug 2018; for review 23 Aug 2018; accepted 15 Apr 2019 (C) 2019 SBMO/SBMag (cc) BY 1 ISSN 2179-1074 